Original article

\title{
Differences in cognitive performance and cognitive decline across European regions: a population-based prospective cohort study
}

\author{
Tomas Formanek ${ }^{\mathrm{a}}$, Anna Kagstrom ${ }^{\mathrm{a}}$, Petr Winkler ${ }^{\mathrm{a}, \mathrm{b}}$, Pavla Cermakova ${ }^{\mathrm{a}, \mathrm{c}, *}$ \\ ${ }^{a}$ National Institute of Mental Health, 25067 Klecany, Czech Republic \\ ${ }^{\mathrm{b}}$ Health Service and Population Research Department, Institute of Psychiatry, Psychology and Neuroscience, King's College London, United Kingdom \\ ' Third Faculty of Medicine, Charles University Prague, Czech Republic
}

\section{A R T I C L E I N F O}

\section{Article history:}

Received 8 January 2019

Received in revised form 4 March 2019

Accepted 6 March 2019

Available online 12 March 2019

\section{Keywords:}

Cognition

Change

Reserve

Epidemiology

\begin{abstract}
A B S T R A C T
Background: A large variation in cognitive performance exists between European regions. However, it is unclear how older Europeans differ in the rate of cognitive decline.

Methods: We analysed data from 22181 individuals (54\% women; median age 71 ) who participated in the Survey on Health, Ageing and Retirement in Europe. Cognition was measured using tests on verbal fluency, immediate and delayed recall. We used linear regression and linear mixed effects regression to examine regional differences in the level of cognitive performance and the rate of cognitive decline. Results: Scandinavians had the highest baseline cognitive scores (mean standardized overall cognitive score 0.3), followed by Western Europeans (mean 0.2), Central and Eastern Europeans (mean 0.1) and individuals from Mediterranean countries (mean -0.4). These differences persisted even after adjustment for sociodemographic and clinical characteristics. The annual cognitive decline in Scandinavia (0.59\%) was approximately two times greater than in Western Europe (0.28\%), Central and Eastern Europe (0.25\%) and Mediterranean countries (0.23\%).

Discussion: There are substantial differences in cognitive performance as well as rates of cognitive decline among the elderly throughout European regions. This might be explained by differing levels of cognitive reserve.
\end{abstract}

(c) 2019 Elsevier Masson SAS. All rights reserved.

\section{Introduction}

The continuous increase in life expectancy is accompanied by a rising prevalence of age-related conditions such as cognitive impairment, which is associated with individual productivity, well-being, physical and mental health and life expectancy [1]. Even subtle deterioration in cognitive performance predicts future development of dementia, which leads affected individuals to a level of cognitive impairment severe enough to interfere with daily functioning and dependency on caregivers [2]. Declining cognitive functions of older adults are, therefore, one of the primary concerns for European countries [1,3,4]. Cognitive impairment has multifactorial aetiology and is likely caused by a combination of genetic susceptibility, environmental factors as well as geneenvironment interactions [1]. Studies link its development with a low level of education, vascular risk factors and cardiovascular

\footnotetext{
* Corresponding author at: National Institute of Mental Health, Topolová 748, Klecany, 250 67, Czech Republic.

E-mail address: Pavla.Cermakova@nudz.cz (P. Cermakova).
}

disease (CVD), depression and social isolation, indicating that the risk of cognitive decline is at least partially modifiable [1,5].

Large differences in cognitive abilities exist across European regions. Older adults in Scandinavia have been reported as having the highest cognitive performance of all Europeans, while their counterparts in southern Europe show the lowest cognitive performance [6,7]. However, it has been acknowledged that there is limited evidence about cognitive ageing from countries in Central and Eastern Europe (CEE) [8]. The varying levels of cognitive performance of older Europeans have been postulated to reflect differences in cognitive reserve, defined as the capacity to cope with neuropathology, delaying the onset of clinical expression of dementia $[9,10]$. Individuals in different European regions have grown up in profoundly different socioeconomic conditions and have been exposed to varying levels of educational and occupational opportunities, social and physical activity, life styles and quality in health care over their life-course [11,12]. These factors may provide them protection in the form of reserve, facilitating the maintenance of cognition despite cumulative neuropathology [12-14].

Few previous studies on life-course and cognitive reserve have been longitudinal in design [6,15-17], therefore, it is largely 
unclear how Europeans differ in rates of cognitive decline. There is also inconsistent evidence about how levels of cognitive performance relate to trajectories of declining cognitive functions. Some authors suggest that high performing individuals with a large cognitive reserve, show a steeper decline in cognition [18-20], while others indicate the opposite [21,22] or no difference [23], relative to individuals who perform on a lower level. A clearer understanding of the factors associated with the speed of cognitive decline will be necessary to help the nations, which are most challenged by the ageing population.

The aim of this study is to use a cohort of nationally representative samples from 17 countries to compare the level of cognitive performance and rate of cognitive decline in 4 European regions: Western Europe, Scandinavia, Mediterranean countries, and CEE. Also, the study aims to elucidate mechanisms through which social and clinical factors shape cognitive ageing across Europe.

\section{Methods}

\subsection{Source of data}

We conducted a prospective, longitudinal cohort study, using data from the Survey on Health, Ageing and Retirement in Europe (SHARE). SHARE is a multidisciplinary, pan-European study that was established with the aim to understand the trajectories of health, social network and economic conditions of aging population in 27 European countries and Israel, as previously described in detail [24]. Briefly, eligible study participants are persons aged at least 50 years and possibly their partners, irrespective of age. New individuals are enrolled at every wave as refreshment samples in order to compensate for the drop out of participants. Data collection is performed by a computer-assisted personal interviewing (CAPI).

The first wave of interviews was conducted in 2004-2006. Five subsequent waves followed in approximately 2-years intervals, with the last wave being finished in 2015. SHARE has been repeatedly reviewed and approved by the Ethics Committee of the University of Mannheim. All participants provided a written consent. Their data were pseudo-anonymized and they have been informed about the storage and use of the data and their right to withdraw the consent. The present study was reviewed and approved by the Ethics Committee of the National Institute of Mental Health in Klecany, Czech Republic.

\subsection{Cognition}

The present study uses data on cognitive functions from waves $1,2,4,5$ and 6 , as cognition was not tested in wave 3 . Cognition was assessed using three measures: verbal fluency, immediate recall and delayed recall. Verbal fluency scores were derived from an animal fluency test [25]. The participants were asked to name as many different animals as they could think of within one minute. The verbal fluency score was the sum of acceptable animals. Immediate and delayed recall were extracted from an adapted 10-word delay recall test [26]. The format of the test used in SHARE is based on the Telephone Interview of Cognitive Status-Modified (TICS-M) [27]. Immediate recall score (range 0-10) was the number of recalled words after the interviewer read a list of 10 words from their computer screen. At the end of the cognitive testing session, the participants were asked again to recall any of the words from the list, which captured delayed recall score (range $0-10$ ).

We present the results of cognitive tests at baseline in the following way: We first show distributions of the actual scores of verbal fluency (words, mean $\pm \mathrm{SD}$ ), immediate recall (words, mean $\pm \mathrm{SD}$ ) and delayed recall (words, median and IQR) for each country and region. Next, we created $\mathrm{z}$ scores of each of the three measure and averaged it in order to present a standardized overall cognitive score.

Due to the problematic nature of standardization in longitudinal studies [28], we show results of the longitudinal analysis as follows: In order to present the annual percentage decline in global cognition, a composite cognitive score was created by summing up the results of the 3 cognitive tests, dividing them by the sum of the maximal possible values on the 3 tests (30) and multiplying by 100 . As the animal word fluency test doesn't have an a priori maximal possible value, 100 points were used as the upper limit, which was the maximal value achieved in this study. It was then divided by 10 , in order to have a scale range comparable to the two other tests, which both reach values between 0 and 10 .

In sensitivity analysis, we repeated the longitudinal analysis, using the proportion of maximum scaling (POMS) method [28]. POMS transformed each cognitive measure to a metric from 0 (minimum) to 1 (maximum), by first making the scale range from 0 to the highest value, and then dividing the scores by the highest value [28].

\subsection{Covariates}

We initially identified covariates based on previous literature as sociodemographic and health-related characteristics related to the risk of low cognitive performance and cognitive decline $[1,5,29-34]$. Selected sociodemographic characteristics include age, gender (women vs. men), years of education, civil status (partner vs. no partner), employment status (currently working vs. not working), residence (urban vs. rural). Health-related characteristics are CVD (obtained from combining information about the history of hypertension, diabetes mellitus, stroke, hypercholesterolemia and coronary disease and the use of cardiovascular drugs), physical inactivity (never vigorous nor moderate physical activity vs. physical activity), body mass index (BMI, calculated from self-reported height and weight), smoking (ever smoked daily vs. never), alcohol (drinking more than 2 glasses of alcohol almost every day vs. drinking less) and depressive symptoms (assessed using EURO-D scale [35]).

\subsection{Study sample}

We restricted analysis to individuals who participated in two and more waves, were at least 65 years old and had complete data on all three cognitive measures in at least two waves $(n=29187$; flowchart presented on Fig. 1). We further excluded the following participants: those who did not have citizenship or were not born in the country of interview $(n=2773)$, were diagnosed with Parkinson's disease, Alzheimer's disease, dementia or senility $(n=1887)$ and did not have data on covariates at least in two waves ( $n=2346$ ), leaving the final sample of 22181 individuals from 4 European regions: Western Europe (Austria, Germany, Netherlands, Switzerland, Belgium, Luxembourg; $n=7$ 290), Mediterranean countries (Spain, Italy, France, Greece, Portugal; $\mathrm{n}=6$ 643), Scandinavia (Sweden, Denmark; $\mathrm{n}=3$ 070) and CEE (Czech Republic, Poland, Slovenia, Estonia; $n=5$ 178). We have defined the European regions as in the previous publication [33]. The mean follow-up time was 4.8 years \pm standard deviation (SD) $3.1 ; 55 \%$ of the study sample had cognitive measures in three and more waves.

\subsection{Statistical analysis}

\subsubsection{Cross-sectional analysis at baseline}

We present descriptive data as frequency (n, \%), means \pm SD or median and interquartile range (IQR). To compare baseline 


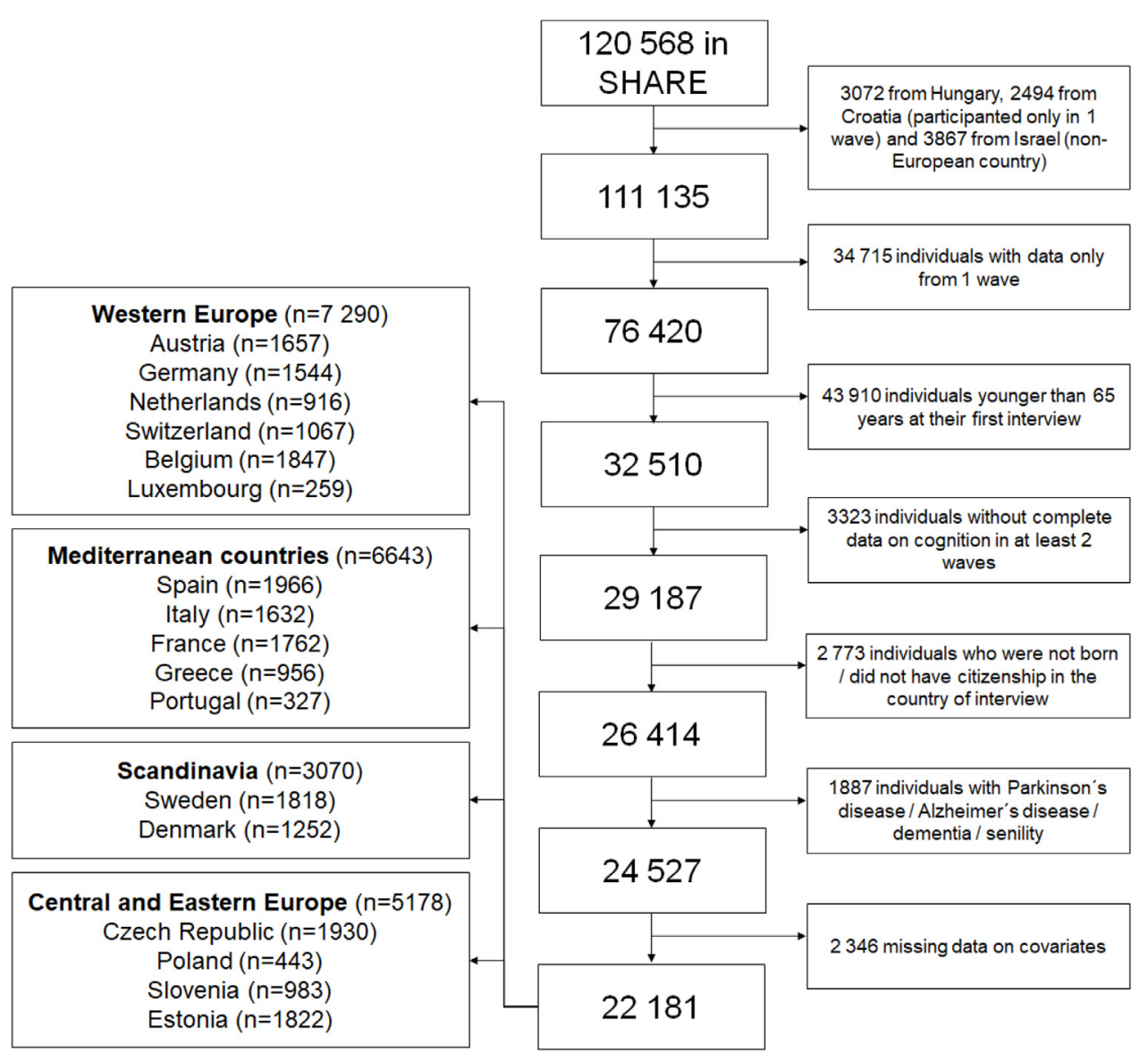

Fig. 1. Selection of the analytical sample.

characteristics of the participants between the 4 regions, we used One-Way Analysis of Variance (ANOVA) for continuous variables with normal distribution, Kruskal-Wallis for continuous variables with skewed distribution and $\chi^{2}$ test for binary variables.

We employed linear regression to estimate B coefficients with 95\% confidence intervals (CI) for the associations of European regions (used as dummy variables, with Western Europe as reference category) using the transformed $\mathrm{z}$ scores for verbal fluency, immediate recall and delayed recall. Further, we averaged the $\mathrm{z}$ scores for the three measures and used the mean for an overall cognitive score. We first adjusted the models for age and gender. We then created the final model by also controlling for potentially modifiable factors such as education, civil status, employment status, residence, CVD, physical inactivity, BMI, smoking, alcohol and depressive symptoms. We included respective variables in the final model if they were significantly associated with the cognitive score at the level of $\mathrm{p}<.05$ or improved the $\mathrm{R}^{2}$ of the model.

\subsubsection{Longitudinal analysis}

To study the rate of cognitive decline over time, we used linear mixed effects models as they are appropriate for the analysis of repeated measures in unbalanced datasets. We estimated the annual decline in scores of verbal fluency, immediate recall and delayed recall and composite cognitive score separately for the 4 European regions. We constructed linear mixed models with the respondents set as random intercepts, the time in years between waves of study as a random slope and also as a fixed effect and all covariates as fixed effects.

To determine the model with the best data fit, we ran several sets of models, stepwise adding groups of covariates: Model 1 was adjusted for baseline age and gender; Model 2 also for education, partner in household, living in a city, working at present; Model 3 also for depression, alcohol use and smoking; and Model 4 also for CVD, BMI and physical inactivity. To be able to compare the models, we used only complete cases that had a valid value on all of the variables of interest. The final model was chosen based on Akaike's information criterion (AIC).

We conducted two sets of sensitivity analysis in order to test the robustness of the findings. Because participants with missing data on cognitive tests in this population were found to be older, less educated and more frequently men [12], which could bias our estimates due to selection, we repeated the main analysis using imputed values on missing data for cognitive measures. Second, we re-ran the analysis including individuals diagnosed with Parkinson's disease, Alzheimer's disease, dementia or senility in the analytical sample. Given the large sample size high risk of type 1 error, we consider a level of $\mathrm{p}<.001$ statistically significant. Data was analysed with STATA (Version 15).

\section{Results}

\subsection{Cross-sectional analysis at baseline}

The sample consisted of 22181 individuals (54\% women; median age 71 years, IQR 8). At baseline, participants from Scandinavia had the highest cognitive scores (verbal fluency mean $22 \pm$ SD 7 ; immediate recall mean $5 \pm$ SD 2; delayed recall median 4, IQR 2), while individuals from Mediterranean countries had the lowest (verbal fluency mean $15 \pm$ SD 6; immediate recall mean $4 \pm \mathrm{SD} 2$; delayed recall median 3, IQR 3; Table 1). Distributions of the cognitive scores by each country are presented in Supplemental Table S1. 
Table 1

Baseline characteristics of participants.

\begin{tabular}{|c|c|c|c|c|c|}
\hline & Western Europe $(\mathrm{n}=7$ 290) & Mediterranean countries ( $n=6643$ ) & Scandinavia $(\mathrm{n}=3070)$ & CEE $(n=5178)$ & $\mathrm{p}$ value \\
\hline \multicolumn{6}{|l|}{ Cognitive functions } \\
\hline Verbal fluency, mean \pm SD & $20.1 \pm 6.8$ & $14.9 \pm 6.1$ & $22.0 \pm 6.5$ & $20.0 \pm 6.8$ & $<.001$ \\
\hline Immediate recall, mean \pm SD & $5.1 \pm 1.6$ & $4.1 \pm 1.7$ & $5.2 \pm 1.6$ & $4.9 \pm 1.7$ & $<.001$ \\
\hline Delayed recall, median (IQR) & $4(3)$ & $3(3)$ & $4(2)$ & $3(2)$ & $<.001$ \\
\hline Overall cognition, mean \pm SD & $0.2 \pm 0.8$ & $-0.4 \pm 0.7$ & $0.3 \pm 0.7$ & $0.1 \pm 0.8$ & $<.001$ \\
\hline \multicolumn{6}{|l|}{ Sociodemographic characteristics } \\
\hline Age, median (IQR) & $71(8)$ & $72(8)$ & $71(9)$ & $71(8)$ & 0.3 \\
\hline Women, n (\%) & $3814(52)$ & $3504(53)$ & $1574(51)$ & $3086(60)$ & $<.001$ \\
\hline Education $\geq 14$ years, $\mathrm{n}(\%)$ & $1419(20)$ & $680(10)$ & $960(31)$ & $1048(20)$ & $<.001$ \\
\hline Partner, n (\%) & $5109(70)$ & $4750(72)$ & $2306(75)$ & $3392(66)$ & $<.001$ \\
\hline Currently working, n (\%) & $129(2)$ & $105(2)$ & $129(4)$ & $273(5)$ & $<.001$ \\
\hline Urban residence, n (\%) & $2993(41)$ & $2885(43)$ & $1754(57)$ & $1860(36)$ & $<.001$ \\
\hline \multicolumn{6}{|l|}{ Health-related characteristics } \\
\hline Cardiovascular disease, n (\%) & 5027 (69) & $4746(71)$ & $1926(63)$ & $3975(77)$ & $<.001$ \\
\hline Physical inactivity, n (\%) & $644(9)$ & $928(14)$ & $115(4)$ & $680(13)$ & $<.001$ \\
\hline Body mass index, mean \pm SD & $26.6 \pm 4.3$ & $26.8 \pm 4.1$ & $25.9 \pm 4.0$ & $27.8 \pm 4.5$ & $<.001$ \\
\hline Smoking, n (\%) & $4395(60)$ & $3638(55)$ & $2196(72)$ & $2304(45)$ & $<.001$ \\
\hline Alcohol, n (\%) & $1026(14)$ & $925(14)$ & $423(14)$ & $734(14)$ & 0.96 \\
\hline Depressive score, median (IQR) & $2(3)$ & $2(3)$ & $1(3)$ & $2(3)$ & $<.001$ \\
\hline
\end{tabular}

$\mathrm{SD}$, standard deviation; IQR, interquartile range; CEE, Central and Eastern Europe.

There were no differences in age among European regions, but there were more women in CEE. The European regions differed in all sociodemographic characteristics. For example, the proportion of individuals with at least 14 years of education was the highest in Scandinavia (31\%) and the lowest in Mediterranean countries (10\%). Furthermore, individuals from the four European regions differed in several clinical factors. For example, the frequency of physically inactive persons is the highest in Mediterranean countries (14\%) and lowest in Scandinavia (4\%).

Compared to Western Europe and adjusting for age and gender (Table 2), Mediterranean countries (B -0.61; 95\% CI -0.63 to -0.58 ) and CEE (B $-0.13 ; 95 \%$ CI -0.16 to -0.11 ) were associated with a lower level of overall cognitive performance, while Scandinavia was associated with a higher level (B 0.14; 95\% CI 0.11 to 0.17 ). When adding sociodemographic and clinical factors into the model, the associations remained statistically significant. These trends were similar across cognitive domains.

\subsection{Longitudinal analysis}

he annual decline in the composite cognitive score was considerably higher in Scandinavia (0.59\%), than in Western Europe ( $0.28 \%)$, CEE ( $0.25 \%$ ) or in Mediterranean countries $(0.23 \%)$, adjusting for baseline age and gender. The rate of cognitive decline was attenuated when clinical and demographic factors were added into the models. Model 4, which includes all confounders, was found to be the best according to AIC (Table 3). Then, the highest rate of annual decline in composite cognitive score was still in Scandinavia $(0.49 \%)$, while the 3 other regions had a similarly lower rate of cognitive decline: Western Europe 0.18\%, Mediterranean countries $0.17 \%$ and CEE $0.16 \%$. These trends were similar across cognitive domains (Supplemental Table S2) as well as in

Table 2

Associations of European regions with baseline cognitive scores.

\begin{tabular}{|c|c|c|c|c|c|c|}
\hline & \multicolumn{2}{|c|}{ Mediterranean countries } & \multicolumn{2}{|l|}{ Scandinavia } & \multicolumn{2}{|l|}{ CEE } \\
\hline & $\mathrm{B}(95 \% \mathrm{CI})$ & beta & B $(95 \% \mathrm{CI})$ & beta & $\mathrm{B}(95 \% \mathrm{CI})$ & beta \\
\hline \multicolumn{7}{|l|}{ Verbal fluency } \\
\hline Adjusted for age and gender & $-0.73(-0.76 ;-0.70)^{*}$ & -0.33 & $0.27(0.23 ; 0.31)^{*}$ & 0.09 & $-0.002(-0.03 ; 0.03)$ & -0.001 \\
\hline Final model & $-0.56(-0.59 ;-0.53)^{*}$ & -0.23 & $0.21(0.17 ; 0.25)^{*}$ & 0.07 & $-0.01(-0.04 ; 0.03)$ & -0.003 \\
\hline \multicolumn{7}{|l|}{ Immediate recall } \\
\hline Adjusted for age and gender & $-0.61(-0.64 ;-0.57)^{*}$ & -0.28 & $0.03(-0.01 ; 0.07)$ & 0.01 & $-0.15(-0.18 ;-0.12)^{*}$ & -0.06 \\
\hline Final model & $-0.43(-0.46 ;-0.39)^{*}$ & -0.20 & $-0.03(-0.07 ; 0.004)$ & -0.01 & $-0.15(-0.19 ;-0.12)^{*}$ & -0.07 \\
\hline \multicolumn{7}{|l|}{ Delayed recall } \\
\hline Adjusted for age and gender & $-0.49(-0.52 ;-0.46)^{*}$ & -0.23 & $0.11(0.07 ; 0.15)^{*}$ & 0.04 & $-0.25(-0.28 ;-0.22)^{*}$ & -0.11 \\
\hline Final model & $-0.32(-0.36 ;-0.29)^{*}$ & -0.15 & $0.05(0.01 ; 0.09)$ & 0.02 & $-0.24(-0.27 ;-0.21)^{*}$ & -0.10 \\
\hline \multicolumn{7}{|l|}{ Overall cognition } \\
\hline Adjusted for age and gender & $-0.61(-0.63 ;-0.58)^{*}$ & -0.34 & $0.14(0.11 ; 0.17)^{*}$ & 0.06 & $-0.13(-0.16 ;-0.11)^{*}$ & -0.07 \\
\hline Final model & $-0.44(-0.46 ;-0.41)^{*}$ & -0.24 & $0.07(0.05 ; 0.10)^{*}$ & 0.03 & $-0.14(-0.16 ;-0.11)^{*}$ & -0.07 \\
\hline
\end{tabular}

CEE, Central and Eastern Europe; CI, confidence interval.

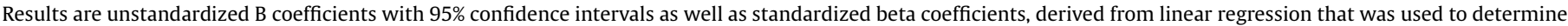

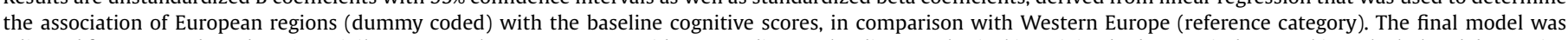

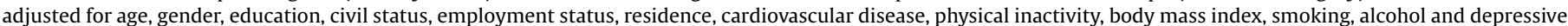
symptoms (covariates were kept in the model, if they were significantly associated with the dependent variable or improved $\mathrm{R}^{2}$ of the model). $p<.001$. 
Table 3

Annual percentage decline in composite cognitive score in European regions.

\begin{tabular}{|c|c|c|c|c|}
\hline \multirow[t]{2}{*}{ Region } & \multicolumn{4}{|l|}{ Model } \\
\hline & $\begin{array}{l}1 \\
\mathrm{~B}(95 \% \mathrm{CI})\end{array}$ & $\begin{array}{l}2 \\
\mathrm{~B}(95 \% \mathrm{CI})\end{array}$ & $\begin{array}{l}3 \\
\mathrm{~B}(95 \% \mathrm{CI})\end{array}$ & $\begin{array}{l}4 \\
\mathrm{~B}(95 \% \mathrm{CI})\end{array}$ \\
\hline Western Europe & $-0.28(-0.33 ;-0.23)$ & $-0.26(-0.30 ;-0.21)$ & $-0.21(-0.26 ;-0.16)$ & $-0.18(-0.23 ;-0.13)$ \\
\hline Mediterranean countries & $-0.23(-0.28 ;-0.19)$ & $-0.22(-0.26 ;-0.18)$ & $-0.18(-0.23 ;-0.14)$ & $-0.17(-0.21 ;-0.13)$ \\
\hline Scandinavia & $-0.59(-0.66 ;-0.53)$ & $-0.58(-0.65 ;-0.52)$ & $-0.55(-0.61 ;-0.48)$ & $-0.49(-0.56 ;-0.43)$ \\
\hline CEE & $-0.25(-0.33 ;-0.17)$ & $-0.22(-0.30 ;-0.14)$ & $-0.18(-0.26 ;-0.10)$ & $-0.16(-0.24 ;-0.08)$ \\
\hline
\end{tabular}

$\mathrm{CI}$, confidence interval; CEE, Central and Eastern Europe.

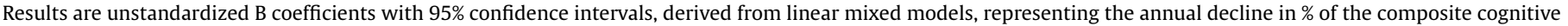
score. All associations are significant at the level of $\mathrm{p}<.001$

Model 1: adjusted for baseline age and gender.

Model 2: + education, civil status, employment status, residence.

Model 3: + depressive symptoms, alcohol, smoking.

Model 4: + cardiovascular disease, body mass index, physical inactivity.

Akaike information criterion:

Model 1: Western Europe 149731; Mediterranean countries 132519; Scandinavia 62771; CEE 100624.

Model 2: Western Europe 149507; Mediterranean countries 131215; Scandinavia 62463; CEE 99470.

Model 3: Western Europe 149274; Mediterranean countries 130890; Scandinavia 62401; CEE 99160.

Model 4: Western Europe 149180; Mediterranean countries 130842; Scandinavia 62353; CEE 99102.

sensitivity analyses, when imputed values for missing data on cognitive scores were used and persons diagnosed with Parkinson's disease, Alzheimer's disease, dementia or senility were kept in the analytical sample (Supplemental Table S3). Results were also similar when POMS method was used (Supplemental Table S4).

\section{Discussion}

In this prospective cohort study, of more than twenty thousand well-characterized, nationally representative individuals from 17 European countries, we demonstrated a non-trivial variation in cognitive functioning in different European regions and noted a clear, but counterintuitive relationship between the level of cognitive performance and the rate of cognitive decline. We found that older adults in Scandinavia had the greatest level of baseline cognitive performance but also the highest rate of cognitive decline, more than twice as high as their counterparts in other regions of Europe.

Our findings complement previous work on inequalities in cognitive functioning of older adults in Europe [6,7,9,15-17], the global literature on geographical differences in cognition measured by educational achievements [36,37] and international variation in human cognitive capital and intelligence $[38,39]$. This study is unique for 3 reasons: 1) It uses a longitudinal design, which only few previous studies have [6,15-17]; 2) participants constitute a large sample of older adults, including countries from CEE, which have been underrepresented in previous studies $[1,40]$ and 3 ) it uses a complex measure of cognitive functions. In line with literature [6,7], we show that Scandinavians have the highest level of cognitive performance from older individuals residing in Europe. Expanding on these results, we show that Scandinavians also have the fastest rate of decline in cognitive functions.

Previous studies have consistently found that high levels of cognitive performance in older adults mirror high levels of cognitive reserve, while the relationship between cognitive reserve and rate of cognitive decline is less clear [23]. SinghManoux and colleagues found within the Whitehall II study that individuals with the greatest cognitive reserve, as indicated by the highest occupational position, experienced a faster rate of cognitive decline when compared to individuals with a lower occupational status [22]. Similarly, in the AHEAD study, a greater decline in memory and verbal fluency was observed in the group with the highest cognitive reserve, which was defined by income [21]. Although these studies operationalize cognitive reserve in different ways, by occupational status or income, their findings can be used to help explain the relationship between the level of cognitive performance and the rate of cognitive decline found in our study. By interpreting these past findings in combination with the results from the current study, we propose that higher cognitive reserve is associated with a higher rate of cognitive decline.

This growing evidence points to an explanation for why Scandinavians experience a faster rate of cognitive decline when compared to other regions. Consequences of advantages associated with strong welfare states enabling Scandinavian citizens to engage in intellectually stimulating occupations and other reserve enhancing activities over the whole life-course [12,13] are reflected in a large cognitive reserve, which is mirrored in the high levels of cognitive performance. With more cognitive reserve at baseline, individuals, such as those in Scandinavia, experience a faster decline, possibly because there are more neural resources to lose. Previous studies have suggested that higher cognitive reserve is associated with delayed onset of clinical manifestation of dementia and a larger degree of neurodegenerative pathology upon the onset of symptoms [10]. Persons with a higher reserve may cope with neuropathology for a longer time. However, once they reach a certain threshold, when their reserve mechanisms are depleted, they may experience faster cognitive deterioration than their counterparts with a lower cognitive reserve [41].

The regional differences in the level of cognitive performance and the rate of cognitive decline were attenuated in the models by adding information about several sociodemographic and clinical risk factors. This is in line with the view that interventions to enhance social engagement and health of older adults, in particular cardiovascular parameters and mental health, may improve their cognitive abilities $[3,42]$. However, these factors did not fully explain the variation in cognitive ageing, suggesting that exposure to other factors across the life-course may have played a role in determining the observed differences. These could include earlylife experiences, nutrition, perceived stress, social and intellectual stimulation as well as genetic and epigenetic factors [13].

Several limitations of this study need to be mentioned. Firstly, the high frequency of apolipoprotein E allele $\varepsilon 4$ observed in Scandinavia [43], the most important genetic risk factor for sporadic dementia [44], could have influenced our results as the potential overrepresentation of adults with this allele could possibly result in an increased rate of cognitive decline. Moreover, learning effects could have occurred between the waves, which could lead to underestimation of the rate of cognitive decline and to decreased measurement precision. 
Furthermore, it is possible that the faster decline in the population of Scandinavians is the result of statistical phenomena known as regression to the mean, though this possibility is less likely given the large sample size. In addition, our definition of European regions may not completely reflect all contextual similarities between countries.

It has long been believed that cognition declines only few years prior to the diagnosis of dementia and individuals with the lowest cognitive reserve, as indicated by different measures of socioeconomic position, are at the highest risk for its development [10]. We propose that the emphasis on factors earlier in life which affect the trajectory of cognitive decline, even in high performing individuals, could be an important shift in public health policy. An increase in cognitive performance among successive cohorts has been observed in many countries [45]. It may be speculated that cognitive performance is likely to keep improving across Europe and people in other European regions might soon experience the same trajectory as currently observed in Scandinavia. Future studies should disentangle whether cognitive decline in high performing individuals has an effect on their disability and quality of life before they reach the threshold of dementia, including age of diagnosis in relation to life expectancy across different regions.

\section{Funding}

This was supported by the Sustainability for the National Institute of Mental Health" (grant LO1611), with a financial support from the Ministry of Education, Youth and Sports of the Czech Republic. Further, PC was also supported by grant PRIMUS (247066) conducted at The Third Faculty of Medicine, Charles University Prague, Czech Republic. The SHARE data collection has been primarily funded by the European Commission through FP5 (QLK6-CT-2001-00360), FP6 (SHARE-I3: RIICT-2006-062193,COMPARE: CIT5-CT-2005-028857,SHARELIFE: CIT4CT-2006-028812) and FP7 (SHARE-PREP: $N^{\circ} 211909$, SHARE-LEAP: $\mathrm{N}^{\circ}$ 227822, SHARE M4: $\mathrm{N}^{\circ}$ 261982). Additional funding from the German Ministry of Education and Research, the Max Planck Society for the Advancement of Science, the U.S. National Institute on Aging (U01_AG09740-13S2, P01_AG005842, P01_AG08291, P30_AG12815, R21_AG025169, Y1-AG-4553-01, IAG_BSR06-11, OGHA_04-064, HHSN271201300071C) and from various national funding sources is gratefully acknowledged (see $\backslash 1 . \mid 2$.share-project.org).

\section{Appendix A. Supplementary data}

Supplementary material related to this article can be found, in the online version, at doi:https://doi.org/10.1016/j.eurpsy.2019.03.001.

\section{References}

[1] Winblad B, Amouyel P, Andrieu S, Ballard C, Brayne C, Brodaty H, et al. Defeating Alzheimer's disease and other dementias: a priority for European science and society. Lancet Neurol 2016;15:455-532.

[2] Sterniczuk R, Theou O, Rusak B, Rockwood K. Cognitive test performance in relation to health and function in 12 european countries: the SHARE study. Can Geriatr J 2015;18:144-51.

[3] Stuhec M, Keuschler J, Serra-Mestres J, Isetta M. Effects of different antihypertensive medication groups on cognitive function in older patients: a systematic review. Eur Psychiatry 2017:46:1-15.

[4] Wancata J, Musalek M, Alexandrowicz R, Krautgartner M. Number of dementia sufferers in Europe between the years 2000 and 2050. Eur Psychiatry 2003; (18):306-13.

[5] Cermakova P, Muller M, Armstrong AC, Religa D, Bryan RN, Lima JAC, et al. Subclinical cardiac dysfunction and brain health in midlife: CARDIA (Coronary Artery Risk Development in Young Adults) brain magnetic resonance imaging substudy. J Am Heart Assoc 2017;6.

[6] Skirbekk V, Loichinger E, Weber D. Variation in cognitive functioning as a refined approach to comparing aging across countries. Proc Natl Acad Sci 2012;109:770-4.

[7] Weber D, Skirbekk V, Freund I, Herlitz A. The changing face of cognitive gender differences in Europe. Proc Natl Acad Sci U S A 2014;111:11673-8.
[8] Wu YT, Fratiglioni L, Matthews FE, Lobo A, Breteler MM, Skoog I, et al. Dementia in western Europe: epidemiological evidence and implications for policy making. Lancet Neurol 2016;15:116-24.

[9] Cadar D, Robitaille A, Clouston S, Hofer SM, Piccinin AM, et al. An international evaluation of cognitive reserve and memory changes in early old age in ten European countries. Neuroepidemiology 2017;48:9-20.

[10] Stern Y. Cognitive reserve in ageing and Alzheimer's disease. Lancet Neurol 2012:11:1006-12.

[11] Doblhammer G, van den Berg GJ, Fritze T. Economic conditions at the time of birth and cognitive abilities late in life: evidence from ten European countries. PLoS One 2013;8:e74915.

[12] Cermakova P, Formanek T, Kagstrom A, Winkler P. Socioeconomic position in childhood and cognitive aging in Europe. Neurology 2018;91:e1602-10.

[13] Wang HX, MacDonald SW, Dekhtyar S, Fratiglioni L. Association of lifelong exposure to cognitive reserve-enhancing factors with dementia risk: a community-based cohort study. PLoS Med 2017;14:e1002251.

[14] Perneczky R, Alexopoulos P, Wagenpfeil S, Bickel H, Kurz A. Head circumference, apolipoprotein E genotype and cognition in the Bavarian School Sisters Study. Eur Psychiatry 2012;27:219-22.

[15] Mazzuco S, Meggiolaro S, Ongaro F, Toffolutti V. Living arrangement and cognitive decline among older people in Europe. Ageing Soc 2016;37:111133.

[16] Cadar D, Robitaille A, Clouston S, Hofer SM, Piccinin AM, et al. An international evaluation of cognitive reserve and memory changes in early old age in 10 European countries. Neuroepidemiology 2017:48:9-20.

[17] Hessel P, Kinge JM, Skirbekk V, Staudinger UM. Trends and determinants of the Flynn effect in cognitive functioning among older individuals in 10 European countries. J Epidemiol Community Health 2018 jech-2017-209979.

[18] Glymour MM, Tzourio C, Dufouil C. Is cognitive aging predicted by one's own or one's parents' educational level? Results from the three-city study. Am J Epidemiol 2012;175:750-9.

[19] Colsher PL, Wallace RB. Longitudinal application of cognitive function measures in a defined population of community-dwelling elders. Ann Epidemiol 1991;1:215-30.

[20] Evans DA, Beckett LA, Albert MS, Hebert LE, Scherr PA, Funkenstein HH, et al. Level of education and change in cognitive function in a community population of older persons. Ann Epidemiol 1993;3:71-7.

[21] Karlamangla AS, Miller-Martinez D, Aneshensel CS, Seeman TE, Wight RG, Chodosh J. Trajectories of cognitive function in late life in the United States: demographic and socioeconomic predictors. Am J Epidemiol 2009; 170:331-42.

[22] Singh-Manoux A, Marmot MG, Glymour M, Sabia S, Kivimäki M, et al. Does cognitive reserve shape cognitive decline? Ann Neurol 2011;70:296-304.

[23] Soldan A, Pettigrew C, Cai Q, Wang J, Wang MC, Moghekar A, et al. Cognitive reserve and long-term change in cognition in aging and preclinical Alzheimer's disease. Neurobiol Aging 2017;60:164-72.

[24] Borsch-Supan A, Brandt M, Hunkler C, Kneip T, Korbmacher J, et al. Data resource profile: the survey of health, ageing and retirement in Europe (SHARE). Int J Epidemiol 2013;42:992-1001.

[25] Henley NM. A psychological study of the semantics of animal terms. J Verbal Learning Verbal Behav 1969;8:176-84.

[26] Harris SJ, Dowson JH. Recall of a 10-word list in the assessment of dementia in the elderly. Br J Psychiatry 1982;141:524-7.

[27] Brandt J, Spencer M, Folstein M. The telephone interview for cognitive status. Neuropsychiatry Neuropsychol Behav Neurol 1988;1:111-7.

[28] Moeller J. A word on standardization in longitudinal studies: don't. Front Psychol 2015;6:1389.

[29] Cermakova P, Nelson M, Secnik J, Garcia-Ptacek S, Johnell K, et al. Living Alone with Alzheimer's Disease: Data from SveDem, the Swedish Dementia Registry. J Alzheimers Dis 2017;58:1265-72.

[30] Cermakova P, Szummer K, Johnell K, Fastbom J, Winblad B, Eriksdotter M, et al. Management of Acute Myocardial Infarction in Patients With Dementia: Data From SveDem, the Swedish Dementia Registry. J Am Med Dir Assoc 2017; $18: 19-23$.

[31] Secnik J, Cermakova P, Fereshtehnejad SM, Dannberg P, Johnell K, Fastbom J, et al. Diabetes in a large dementia cohort: clinical characteristics and treatment from the swedish dementia registry. Diabetes Care 2017;40:1159-66.

[32] Enache D, Fereshtehnejad SM, Kareholt I, Cermakova P, Garcia-Ptacek S, et al. Antidepressants and mortality risk in a dementia cohort: data from SveDem, the Swedish Dementia Registry. Acta Psychiatr Scand 2016;134:430-40.

[33] Horackova K, Kopecek M, Machu V, Kagstrom A, Aarsland D, Motlova LB, et al. Prevalence of late-life depression and gap in mental health service use across European regions. Eur Psychiatry 2019;57:19-25.

[34] Cermakova P, Ding J, Meirelles O, Reis J, Religa D, Schreiner PJ, et al. Carotid intima-media thickness and markers of brain health in a bi-racial middle-aged cohort: CARDIA Brain MRI Sub-study. The journals of gerontology Series A. Biological sciences and medical sciences. 2019.

[35] Prince MJ, Reischies F, Beekman AT, Fuhrer R, Jonker C, Kivela SL, et al. Development of the EURO-D scale-a European, Union initiative to compare symptoms of depression in 14 European centres. Br J Psychiatry 1999;174:330-8.

[36] Altinok N, Angrist N, Patrinos HA. Global data set on education quality (1965-2015). The World Bank; 2018. 
[37] Rindermann $H$. The g-factor of international cognitive ability comparisons: the homogeneity of results in PISA, TIMSS, PIRLS and IQ-tests across nations. Eur J Pers 2007;21:667-706.

[38] Dutton E. Cognitive capitalism: human capital and the wellbeing of nations. J Soc Polit Econ Stud 2017;43:351-4.

[39] Lynn R, Vanhanen T. Intelligence: a unifying construct for the social sciences. Ulster Institute for Social Research; 2012.

[40] Winkler P, Formanek T, Mlada K, Cermakova P. The CZEch Mental health Study (CZEMS): study rationale, design, and methods. Int J Methods Psychiatr Res 2018 e1728.

[41] Amieva H, Mokri H, Le Goff M, Meillon C, Jacamin-Gadda H, Foubert-Samier A, et al. Compensatory mechanisms in higher-educated subjects with Alzheimer's disease: a study of 20 years of cognitive decline. Brain 2014;137:1167-75.

[42] Ngandu T, Lehtisalo J, Solomon A, Levalahti E, Ahtiluoto S, Antikainen R, et al. A 2 year multidomain intervention of diet, exercise, cognitive training, and vascular risk monitoring versus control to prevent cognitive decline in at-risk elderly people (FINGER): a randomised controlled trial. Lancet 2015;385:2255-63.

[43] Ward A, Crean S, Mercaldi CJ, Collins JM, Boyd D, Cook MN, et al. Prevalence of apolipoprotein E4 genotype and homozygotes (APOE e4/4) among patients diagnosed with Alzheimer's disease: a systematic review and meta-analysis. Neuroepidemiology 2012;38:1-17.

[44] Lindsay J, Laurin D, Verreault R, Hébert R, Helliwell B, Hill GB, et al. Risk factors for Alzheimer's disease: a prospective analysis from the Canadian Study of Health and Aging. Am J Epidemiol 2002;156:445-53.

[45] Sacuiu S, Gustafson D, Sjögren M, Guo X, Östling S, Johansson B, et al. Secular changes in cognitive predictors of dementia and mortality in 70-year-olds. Neurology 2010;75:779-85. 